\title{
Photodegradation of $\alpha$-Pinene Secondary Organic Aerosol Dominated by Moderately Oxidized Molecules
}

\author{
Veronika Pospisilova, David M. Bell,* Houssni Lamkaddam, Amelie Bertrand, Liwei Wang, \\ Deepika Bhattu, Xueqin Zhou, Josef Dommen, Andre S.H. Prevot, Urs Baltensperger, Imad El Haddad, \\ and Jay G. Slowik*
}

Cite This: Environ. Sci. Technol. 2021, 55, 6936-6943

Read Online

ACCESS |

山ll Metrics \& More

回国 Article Recommendations

SI Supporting Information

ABSTRACT: Atmospheric secondary organic aerosol (SOA) undergoes chemical and physical changes when exposed to UV radiation, affecting the atmospheric lifetime of the involved molecules. However, these photolytic processes remain poorly constrained. Here, we present a study aimed at characterizing, at a molecular level and in real time, the chemical composition of $\alpha$-pinene SOA exposed to UV-A light at 50\% relative humidity in an atmospheric simulation chamber. Significant SOA mass loss is observed at high loadings $\left(\sim 100 \mu \mathrm{g} \mathrm{m}^{-3}\right)$, whereas the effect is less prevalent at lower loadings $\left(\sim 20 \mu \mathrm{g} \mathrm{m}^{-3}\right)$. For the vast majority of molecules measured by the extractive electrospray time-of-flight mass spectrometer, there is a fraction that is photoactive and decays when

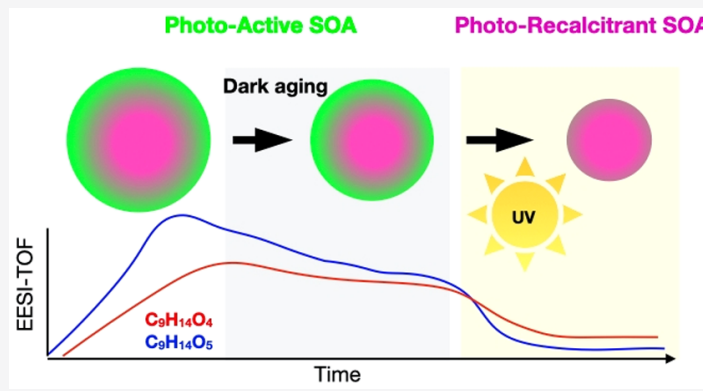
exposed to UV-A radiation and a fraction that appears photorecalcitrant. The molecules that are most photoactive contain between 4 and 6 oxygen atoms, while the more highly oxygenated compounds and dimers do not exhibit significant decay. Overall, photolysis results in a reduction of the volatility of SOA, which cannot be explained by simple evaporative losses but requires either a change in volatility related to changes in functional groups or a change in physical parameters (i.e., viscosity).

\section{INTRODUCTION}

Atmospheric aerosol particles scatter and absorb solar radiation and act as cloud condensation nuclei for tropospheric clouds, changing cloud albedo and lifetime. As such, they affect the radiative balance of the Earth and hence play an important role in the Earth's climate. ${ }^{1}$ A large fraction of the atmospheric aerosol mass is secondary organic aerosol (SOA), formed through the nucleation, condensation, or reactive uptake of the oxidation products of volatile organic compounds (VOCs)., Several processes may alter the condensed-phase organic chemical composition and physical properties (e.g., volatility and viscosity). Due to the complexity of SOA and the challenges related to its analysis, the elucidation of these processes remains elusive.

Recent studies have demonstrated that particle phase reactions occurring in the dark play an important role in the fate of hydroperoxides and other reactive oxygen species (ROS), producing smaller, more volatile compounds that may repartition into the gas phase. ${ }^{4-6}$ Photolytic reactions can have similar effects. ${ }^{7-12}$ Photolysis of oxygenated VOCs, for example, aldehydes, is a well-established source of radicals in the gas phase and significantly affects atmospheric composition and VOC lifetimes. ${ }^{13-15}$ However, little is known about the effects of UV-radiation on the semivolatile and low-volatility oxygenated molecules present in SOA. It has been shown that under UV lights, aerosol yields decrease by $20-40 \%$ for the $\alpha$-pinene ozonolysis system. ${ }^{16}$ A decrease in less oxygenated ions was observed in resuspended SOA by Wong et al., resulting in SOA with a higher atomic $\mathrm{O} / \mathrm{C}$ ratio upon irradiation. ${ }^{17}$ Likewise, Eppstein et al. reported a decrease in the contribution of compounds containing one oxygen atom and an increase of the contribution of more oxygenated compounds, implying that the lower $\mathrm{O} / \mathrm{C}$ compounds in the particles photolyze at a faster rate. ${ }^{18}$ This study also showed a significant net loss in the peroxide content after UV exposure. In contrast, Krapf et al. and Bateman et al. reported no significant net change in the total peroxide content with or without UV lights. ${ }^{5,19}$ O'Brien and Kroll reported that a large fraction of the photoresistant material is present in $\alpha$-pinene SOA formed under dry conditions, ${ }^{20}$ while other studies found only a minor change in the molecular composition of irradiated SOA. ${ }^{45,46}$ A follow-up study suggested removal of carbonyls in favor of increasing carboxyl and ester functional groups within the first 2 days of irradiation, together with increased dimer and trimer fractions on even longer timescales. ${ }^{21}$ Zawadowicz et al. reported photolysis rates $\left(J_{\text {SOA }}\right)$

Received: October 7, 2020

Revised: March 2, 2021

Accepted: March 3, 2021

Published: May 7, 2021

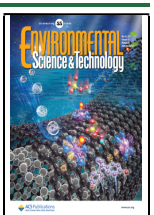



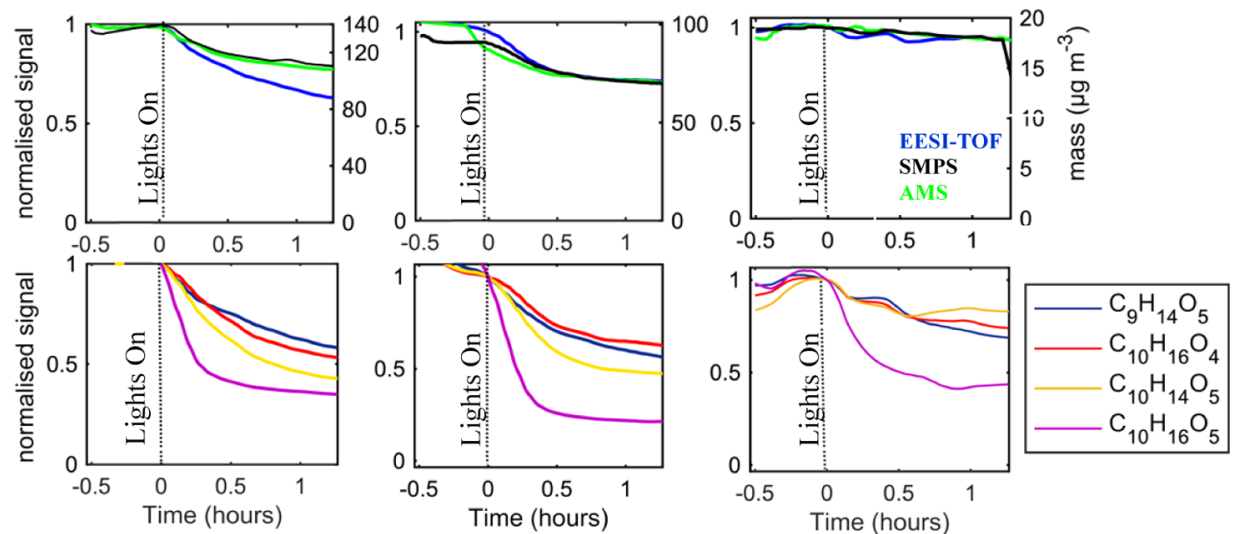

Figure 1. (A) Time evolution of the wall-loss-corrected organic mass measured by the SMPS and AMS and of the total EESI-TOF signal before and after irradiation for three experiments with different initial mass; (B) time evolution of selected ions measured by the EESI-TOF. The dotted line corresponds to the time when the UV lights are turned on $(t=0 \mathrm{~h})$. The signal is normalized to the signal before the lights were turned on.

for a variety of biogenic SOAs formed from both $\mathrm{O}_{3}$ and $\mathrm{OH}$, demonstrating that some fraction of SOA is photorecalcitrant. ${ }^{11}$ The bulk $J_{\mathrm{SOA}}$ values were used to model the SOA formed in the Amazon, showing reductions of 50\% in the SOA mass during the day.

Despite the above evidence that UV radiation significantly alters SOA chemical composition, the specific mechanisms involved are not yet clear. In traditional offline approaches, UV irradiation is applied to water-soluble extracts of SOA particles collected on Teflon filters, raising questions of potential interferences and introducing the possibility of incomplete extraction linked to loss of information. It has been found that, depending on the system, SOA in solution can decompose into smaller volatile products or alternatively produce larger, nonvolatile products. ${ }^{22,23}$ In addition, these studies do not take the interactions between the compounds' photolysis rates and particle microphysics into consideration, for example, viscosity and thermodynamics; and the results may not directly be applicable to SOA species in the particle phase. ${ }^{24,25}$ Online approaches have used the aerosol mass spectrometer (AMS), which relies on highly energetic electron ionization, leading to extensive fragmentation and precluding the retrieval of detailed chemical information. Therefore, the photochemistry of SOA is not yet understood on a molecular level.

Here, we investigated the timescales of the photochemical processes and the effect of short-wavelength solar radiation on SOA produced by the ozonolysis of $\alpha$-pinene in an atmospheric simulation chamber. Upon UV irradiation, the SOA molecular ions were monitored using an extractive electrospray ionization time-of-flight mass spectrometer (EESI-TOF, Tofwerk). ${ }^{26}$ Although the EESI-TOF does not resolve isomers, its novel combination of high chemical and temporal resolution provides new insights into condensed-phase photolysis processes. We have identified the organic compounds in the condensed phase most affected by photolysis. In addition, we conducted isothermal evaporation measurements before and after exposure to UV lights to assess the induced change in the effective volatility of SOA.

Experimental Description. All experiments were performed in an atmospheric simulation chamber located at the Paul Scherrer Institute in Switzerland. The chamber consists of a $\sim 7 \mathrm{~m}^{3}$ bag made of fluorinated ethylene propylene placed in a temperature-controlled housing maintained at $22{ }^{\circ} \mathrm{C}$. Prior to each experiment, the chamber was cleaned by injecting $\sim 1 \mathrm{ppm}$ of $\mathrm{O}_{3}$ into the chamber, increasing the relative humidity $(\mathrm{RH})$ to $100 \%$ and turning on the UV lights for $\sim 1 \mathrm{~h}$. Overnight, the chamber was continuously flushed with dry purified air at $40 \mathrm{~L}$ $\mathrm{min}^{-1}$ from an air generation system (737-250 series, AADCO Instruments, Inc., USA). Following this cleaning procedure, the chamber was considered clean when there were less than 50 particles $\mathrm{cm}^{-3}$, as measured by a scanning mobility particle sizer (SMPS, TSI Incorporated, USA). Before each experiment, the chamber was conditioned by increasing the $\mathrm{RH}$ to $50-55 \%$ and $\mathrm{O}_{3}$ to $100-400$ parts per billion by volume (ppbv) depending on the experiment. The $\mathrm{O}_{3}$ concentration was monitored by a Thermo Environmental Instruments TEI 49C. The chamber was operated in batch mode without additional dilution flow. $\alpha$ Pinene $(1.5-4 \mu \mathrm{L})$, a common model compound to study biogenic SOA, was injected through a heated septum $\left(80^{\circ} \mathrm{C}\right)$ into a line flushed by a high flow of air directly into the chamber, resulting in mixing ratios of $\sim 30-80 \mathrm{ppbv}$, as measured by a proton transfer reaction time-of-flight mass spectrometer (PTRTOF-MS, Ionicon Analytik). ${ }^{27}$ Photochemistry was induced using a set of $40 \mathrm{UV}$ lights (90-100 W, Cleo Performance, Philips). The characteristic emission spectrum of these lights and an in-depth description of the chamber can be found elsewhere. ${ }^{28}$ The $J_{\mathrm{NO}_{2}}$ determined for the UV-A lights in our chamber was $3 \times 10^{-3} \mathrm{~s}^{-1}$. This value is similar to a typical $\mathrm{J}_{\mathrm{NO}_{2}}$ for summer conditions at midlatitudes and a solar zenith angle of $45^{\circ}\left(\sim 4 \times 10^{-3} \mathrm{~s}^{-1}\right)$. Thus, decay rates reported here are relevant under atmospheric conditions.

The particle size distribution $(20-400 \mathrm{~nm})$ was continuously monitored with an SMPS. For conversion of size distributions to mass, an effective density of $1.2 \mathrm{~g} \mathrm{~cm}^{-3}$ was assumed. After more than $95 \%$ of $\alpha$-pinene was depleted in the gas phase, the UV lights were turned on for approximately $1.5 \mathrm{~h}$. The chemical composition of SOA was measured online with a high-resolution time-of-flight aerosol mass spectrometer (HR-ToF-AMS, Aerodyne Research, Inc.) and an extractive electrospray ionization time-of-flight mass spectrometer (EESI-TOF). ${ }^{26}$ The HR-ToF-AMS provides quantitative measurements of bulk OA concentrations and elemental composition and has been described in detail elsewhere. ${ }^{29}$ The EESI-TOF consists of a home-built EESI inlet coupled to an atmospheric pressure interface time-of-flight mass spectrometer (APi-TOF, Tofwerk AG). ${ }^{30}$ The aerosol was sampled at a flow rate of $\sim 0.8 \mathrm{~L} \mathrm{~min}^{-1}$ through an extruded carbon denuder into a plume of charged droplets generated by the electrospray probe. As electrospray 
working solution, a mixture of water: acetonitrile (1:1) doped with $100 \mathrm{ppm} \mathrm{NaI}$ was used. Positive ion spectra were recorded at $1 \mathrm{~Hz}$, and all ions were detected as adducts with $\mathrm{Na}^{+}$. All the signals from the EESI-TOF are reported in terms of the mass flux of ions reaching the microchannel plate detector in the mass spectrometer in attogram per second $\left(\mathrm{ag} \mathrm{s} \mathrm{s}^{-1}\right)$. This was calculated as the product of the measured signal (ions $\mathrm{s}^{-1}$ ) and the molecular weight of the respective ion, excluding the attached $\mathrm{Na}^{+}$. The mass concentrations measured by the SMPS, AMS, and each EESI ion signal were corrected for wall losses. The wall loss rate was based on the decay of the particle number concentration, corrected for coagulation, and calculated separately for dark and UV-irradiated conditions.

\section{RESULTS AND DISCUSSION}

Figure 1A shows the time evolution of the SOA mass, as measured by the SMPS, as well as the normalized total EESITOF signal (calculated as the sum of all identified $\mathrm{C}_{5}-\mathrm{C}_{20}$ molecules) and AMS signal for three experiments, ranging from high $\left(\sim 95-137 \mu \mathrm{g} \mathrm{m}^{-3}\right)$ to low $\left(19 \mu \mathrm{g} \mathrm{m}^{-3}\right)$ SOA mass loading. For "high loading" experiments ( 1 and 2 ), the mean diameter of the number size distribution measured by the SMPS decreases within $1.5 \mathrm{~h}$ of light exposure (Figure S1), corresponding to a $22 \%$ decrease in volume (Figure 1). The normalized AMS aerosol mass measurements agree very well with the decrease in the normalized particle volume measured by the SMPS (Figure 1 ). These findings are consistent with previous studies despite different experimental conditions. ${ }^{17,18}$ Upon the initial decrease, the aerosol mass reaches a steady state. On the other hand, for the "low loading" experiments (3), negligible photolytic loss $(<6 \%)$ on the SOA mass occurs during irradiation (see Table S2).

Figure 1A shows that the normalized total EESI signal decreases more than the mass measured by the SMPS. The difference is largest for the higher loading experiments ( $38 \%-$ EESI-TOF vs $22 \%$-SMPS) compared to the lower loading experiments ( $\sim 9 \%-$ EESI-TOF vs $6 \%-$ SMPS). The systematic differences suggest that the EESI-TOF is less sensitive to the photolysis reaction products and/or photoresistant material than to the bulk nonirradiated SOA, suggesting systematic changes in chemical composition upon irradiation. Systematic changes in composition are consistent with the increase in the $f \mathrm{CO}_{2}^{+} / f \mathrm{C}_{2} \mathrm{H}_{3} \mathrm{O}^{+}$ratio in the AMS during the photolysis duration (Figure S2), indicating an increase in the fraction of more highly oxygenated compounds, for example, carboxylic acids, with photochemistry, as suggested by Wong et al. and Epstein et al. ${ }^{17,18}$

To obtain the decay rates in the total wall loss-corrected particle mass and EESI ion signals, an exponential fitting function was applied using eq 1 .

$$
Y=Y_{\text {fin }}+\left(Y_{0}-Y_{\text {fin }}\right) * \exp ^{-k *\left(t-t_{0}\right)}
$$

Here, $Y$ equals the fitted time series, $Y_{0}$ the initial value, and $k$ the decay rate in $\mathrm{s}^{-1}$. An offset was used corresponding to $Y_{\text {fin }}$ as the final steady state value. While the vast majority of previous studies represent the photolytic decay using an exponential decay without an intercept, in our case, a significant fraction of molecular ions shows a stable nonzero level after $1.5 \mathrm{~h}$ of irradiation. The fit was applied from the time when the lights are turned on $\left(t_{0}\right)$. Examples of the exponential fitting curve for selected ions detected by the EESI are shown as dashed lines in Figure S3. The obtained decay rates of SOA mass and EESI total signal for the high loading experiments 1 and 2 are $4.1-7.6 \times$ $10^{-4} \mathrm{~s}^{-1}$ (see Tables $S 1$ and S2 for $k$ and $Y_{\text {fin }}$, respectively). In the low loading experiment, little to no change in the signal occurs, corresponding to decay rates of $\sim 0.4 \pm 0.3 \times 10^{-4} \mathrm{~s}^{-1}$, with the high uncertainties due to the minimal loss during photolysis. When comparing this study to previous studies using UV-A lamps and taking into account the differences in light intensities, the total SOA decay rates $\left(J_{S O A}\right)$ reported in our study at high mass loadings are on average 5-10 times higher than those observed by Wong et al. ${ }^{17}\left(0.75 \times 10^{-4} \mathrm{~s}^{-1}\right)$ and Henry and Donahue $^{31}\left(0.6 \times 10^{-4} \mathrm{~s}^{-1}\right)$. With $J_{\mathrm{NO}_{2}}=3 \times 10^{-3} \mathrm{~s}^{-1}$, our $J_{\mathrm{SOA}} /$ $\mathrm{J}_{\mathrm{NO}_{2}}$ ratio varies between $\sim 20 \%$ for high loading experiments and $\sim 1 \%$ for low loading experiments. The absorption cross section of $\mathrm{NO}_{2}$ overlaps well with the lights used in our chamber, with a peak in emission at $368 \mathrm{~nm} .{ }^{28}$ In comparison, the absorption cross section of $\alpha$-pinene SOA peaks at lower wavelengths and will overlap more efficiently with the solar spectrum. ${ }^{11,17}$ Therefore, our decay rates should be considered as lower limits. Our results suggest that the mass concentration plays an important role in controlling the bulk decay rate, as well as the decays of specific species present in the particle phase (Figure 1B). Previously reported $J_{\text {SOA }}$ values for $\alpha$-pinene SOA center around $2 \%$ of $\mathrm{J}_{\mathrm{NO}_{2}}$ for experiments with a SOA mass concentration of $\sim 40-70 \mu \mathrm{g} \mathrm{m}^{-3}$.,11 The concentration dependence of $J_{\mathrm{SOA}}$ could be explained by more abundant chromophores in semivolatile species preferentially present at higher loadings. Another explanation could be that isomers of different photostability are present at various loadings; however, we do not want to speculate without further isomer resolved information available. Nevertheless, the dependence on mass loading suggests that using chamber data with high mass loadings may overestimate the role of photolysis for SOA mass and elemental composition in the atmosphere where organic aerosol concentrations are lower. Below, we investigate the impact of photolysis on the SOA molecular composition.

Figure $1 \mathrm{~B}$ shows the time evolutions of selected particulate species $\left(\mathrm{C}_{10} \mathrm{H}_{16} \mathrm{O}_{4-5}, \mathrm{C}_{10} \mathrm{H}_{14} \mathrm{O}_{5}\right.$, and $\left.\mathrm{C}_{9} \mathrm{H}_{14} \mathrm{O}_{5}\right)$ measured by the EESI-TOF for the same experiments as in Figure 1A. Figure 1B highlights the period where the SOA is aged in the presence of UV radiation. Furthermore in Figure S4, we show the full time series for the $\mathrm{C}_{10} \mathrm{H}_{16} \mathrm{O}_{4-8}$ molecules for experiment 2 to highlight the differences between dark aging and those occurring during photolysis. The decay during photolysis is significantly faster than that occurring in the dark (see Table S3), while for highly oxidized molecules, the decay rate is not significantly faster. The photolytic decay rates vary for each molecule, showing that the photolysis of SOA is compound-dependent. This represents the first online measurement of the photolytic decay of SOA at the molecular level. For all ion signals, the fraction remaining $\left(Y_{\text {fin }}\right)$ is found always to be significantly greater than zero (but below 1), with higher $Y_{\text {fin }}$ at low mass loadings. These observations are consistent with recent findings by O'Brien and Kroll, who reported that approximately $\sim 70$ to $90 \%$ of the initial SOA mass is nonresponsive to UV irradiation or does not show measurable photolytic decay on the timescale of their experiments $(\sim 20 \mathrm{~h}) .^{20}$ Our findings show that this is not only true for bulk OA but also for individual EESI-TOF ions. This likely reflects the presence of both photosensitive and photoresistant isomers in the SOA, which cannot be differentiated by the EESI-TOF. However, it is possible that some photolytic processes go undetected by the EESI-TOF. For example, photoisomerization would yield no change in the 
observed ion signal. Furthermore, the steady decay of photolytically unstable ions could be masked by the contribution from the degradation of higher molecular weight species present below the limit of detection. In this case, the SOA mass would not necessarily be affected, as formed molecules could be of sufficiently low volatility to remain in the particle phase. Therefore, we cannot exclude a steady change in the particle phase composition not being detectable by our instrumentation, and consequently, we refer to the remaining fraction as the apparent photorecalcitrant fraction.

To provide a more comprehensive overview of the molecules most affected by photolysis, Figure $2 \mathrm{~A}$ shows the decay rates for

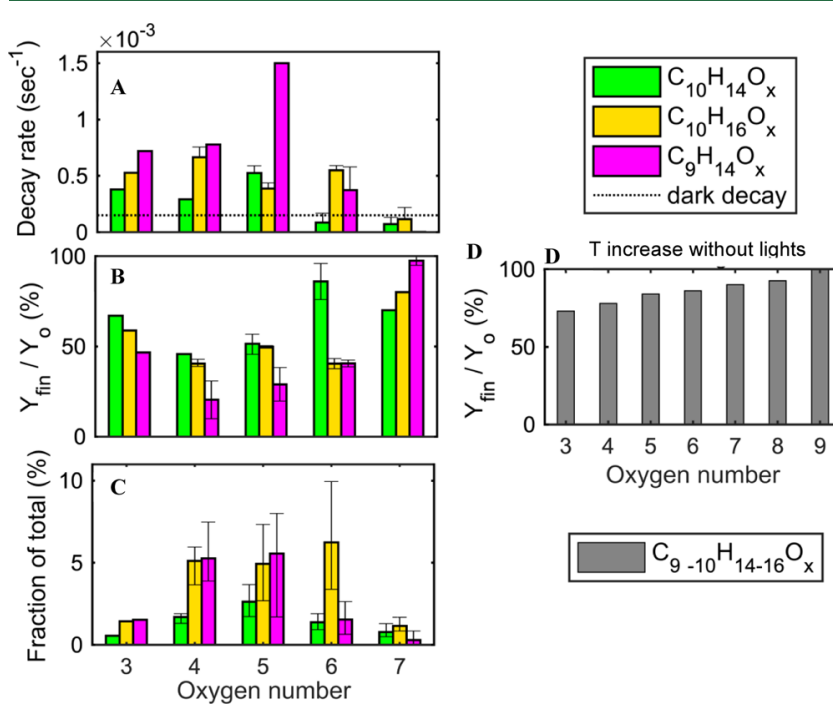

Figure 2. (A) Decay rates of $\mathrm{C}_{10} \mathrm{H}_{14} \mathrm{O}_{3-7}, \mathrm{C}_{10} \mathrm{H}_{16} \mathrm{O}_{3-7}$, and $\mathrm{C}_{9} \mathrm{H}_{14} \mathrm{O}_{3-7}$ ions measured by EESI-TOF during the UV irradiation as a function of number of oxygen atoms. The horizontal dotted line correspond to the bulk dark decay rate $\left(\sim 1.4 \times 10^{-4} \mathrm{~s}^{-1}\right.$ based on our previous study $\left.{ }^{6}\right)$. (B) Relative contribution of signal remaining $\left(Y_{\mathrm{fin}} / Y_{0}\right.$, in percent) determined from the exponential fit to the wall-loss corrected EESITOF signal based on eq 1. (C) Contribution of the selected ions to the total signal measured by the EESI-TOF before the UV irradiation. The error bars correspond to minimum and maximum values observed across experiments 1 and 2. (D) Relative signal remaining after heating the chamber by $3{ }^{\circ} \mathrm{C}$ without UV lights for the sum of the ions $\mathrm{C}_{9-10} \mathrm{H}_{14-16} \mathrm{O}_{3-9}$.

the most abundant groups: $\mathrm{C}_{10} \mathrm{H}_{14} \mathrm{O}_{x}, \mathrm{C}_{10} \mathrm{H}_{16} \mathrm{O}_{x}$, and $\mathrm{C}_{9} \mathrm{H}_{14} \mathrm{O}_{x}$ $(x=3-7)$, as measured by the EESI-TOF for experiments 1 and 2 . The decay rate is determined by an exponential fit to the entire irradiation period, allowing a nonzero $y$-intercept to account for the apparent photorecalcitrant fraction (see eq 1 and Figure S3). The chosen molecules account for $\sim 55 \%$ of the total signal before irradiation. For comparison, Figure $2 \mathrm{~A}$ also includes the dark decay rates taken from our previous study of the same system. ${ }^{6}$ The decay rates with UV irradiation are on average $2-8$ times higher than when aging in the dark without an external stimulus. The error bars show the variability between experiments 1 and 2. For all experiments, the signal-to-noise ratio for $\mathrm{C}_{10} \mathrm{H}_{18} \mathrm{O}_{x}$ was insufficient because such compounds undergo a fast decomposition process in the dark. ${ }^{6}$ From the $\mathrm{C}_{6}-\mathrm{C}_{8}$ ion groups measured by the EESI-TOF, only $\mathrm{C}_{8} \mathrm{H}_{12,14} \mathrm{O}_{4-5}$ and $\mathrm{C}_{7} \mathrm{H}_{12} \mathrm{O}_{5}$ show a fast decay upon irradiation. However, these ions contribute less than $\sim 4 \%$ of the total signal and are therefore not discussed and only included in Figure S6, which shows the relative composition of the particles before and after irradiation. The highest decay rates in Figure $2 \mathrm{~A}$ are found for $\mathrm{C}_{9} \mathrm{H}_{14} \mathrm{O}_{3-5}$, where the average values reach $7 \times 10^{-4} \mathrm{~s}^{-1}, 8 \cdot 10^{-4}$ $\mathrm{s}^{-1}$, and $1.5 \times 10^{-3} \mathrm{~s}^{-1}$, for $\# \mathrm{O}=3,4$, and 5 , respectively. This would correspond to lifetimes of 11-22 min for the photolabile isomer $(\mathrm{s}) . \mathrm{C}_{10} \mathrm{H}_{16} \mathrm{O}_{3-6}$ and $\mathrm{C}_{10} \mathrm{H}_{14} \mathrm{O}_{3-5}$ show lower decay rates $\left(4-6 \cdot 10^{-4} \mathrm{~s}^{-1}\right)$, without a clear trend in the number of oxygen atoms or double bond equivalents.

Figure $2 \mathrm{~B}$ shows the fraction remaining for the same subset of molecules as a function of the number of oxygen atoms. In general, there is a minimum at $\# \mathrm{O}=4$ above which the overall fraction remaining increases again with increasing oxygen content. A trend is seen at the decay rates presented in Figure $2 \mathrm{~A}$, suggesting that the signals of the most oxidized ions are less affected by UV irradiation. However, it is also necessary to consider that a fraction of semivolatile molecules will repartition from the particle phase to the gas phase due to the mass decrease and slight increase of temperature by $\sim 3{ }^{\circ} \mathrm{C}$ during the UV irradiation (Figure S7). For example, considering equilibrium partitioning, the concentrations of particle-phase compounds with saturation vapor concentrations $\left(C^{*}\right)$ of $10 \mu \mathrm{g} \mathrm{m}^{-3}$ and 100 $\mu \mathrm{g} \mathrm{m}^{-3}$ would decrease by $\sim 20 \%$ and $\sim 60 \%$ with the decrease in particle mass observed after $90 \mathrm{~min}$. If repartitioning of organics dominated the changes observed in our study, we would expect the trends in both the rates (Figure 2A) and fraction remaining (Figure 2B) to depend strongly on the oxygen number. To evaluate the effect of temperature, we conducted an additional experiment at high loading without UV irradiation while rapidly increasing the temperature in the chamber by $3{ }^{\circ} \mathrm{C}$ and let the particles age for $1.5 \mathrm{~h}$. The result of this dark "heating" experiment for $\mathrm{C}_{9}-\mathrm{C}_{10}$ molecules is shown in Figure $2 \mathrm{D}$ as the fraction remaining when no UV lights are used. The effect of evaporation and UV lights can be compared directly from Figure 2B,D. Unlike in the photolysis experiments, in Figure 2D, we observe a clear trend with the number of oxygen atoms in the fraction remaining, consistent with the processes being driven by evaporation. The minimal fraction remaining (maximal decrease) is around $28 \%$ for the sum of the most volatile (\#O = 3) species, whereas the decrease is $50 \%$ or more for the irradiated counterparts. This is the highest change in the fraction remaining after $1.5 \mathrm{~h}$, followed by the ions with \#O = $4(\sim 22 \%)$ and with \#O = $5(16 \%)$. During the photolysis experiments, the fraction of such ions however decreases in some cases by even $50 \%$. Additionally, the mass lost during heating was $\sim 4-5 \%$ of the total SOA mass (as measured with an SMPS), compared to the $\sim 20 \%$ loss observed during photolysis. Figure S5A highlights the difference between the heating experiment (exp. 4) and the photolysis experiment (exp. 2) in the time series of the $\mathrm{C}_{10} \mathrm{H}_{16} \mathrm{O}_{4-6}$. There is not a dramatic change in the decay rate during heating when compared to the dark period, while with UV lights, there is a clear change in the decay of each molecular formula. Additionally, Figure S5B shows the SMPS and temperature changes during both experiments. Therefore, repartitioning from heating only partially contributes to the signal loss for semivolatile molecules during the photolysis experiments and the major change is induced by chemical changes due to photolysis and its formation of more volatile species.

We note that the low loading experiments are not included in the analysis of Figure 2 because the total signal decreases only slightly and most ions measured by the EESI-TOF do not exhibit a clearly distinguishable change from the noise (Figure S3), making decay rates difficult to determine. However, the relative composition can be compared pre- versus postphotolysis to 
assess the chemical changes by photolysis and is shown in Figure S6. In both cases, the fraction of $\mathrm{C}_{9}$ and $\mathrm{C}_{10}$ molecules seems to be affected the most, but to a lesser extent at lower loadings. This further suggests that the photoactive isomers may be less abundant at low loadings or that the isomers formed at low loading upon photolysis are less susceptible to evaporation.

To assess the change in the effective volatility of $\alpha$-pinene SOA induced by the UV lights, we performed isothermal evaporation measurements of gas-phase stripped monodisperse SOA particles (see the Supporting Information) before and after photochemical aging. The evaporation data for experiments $1-3$ are presented in Figure 3, where the volume fraction remaining

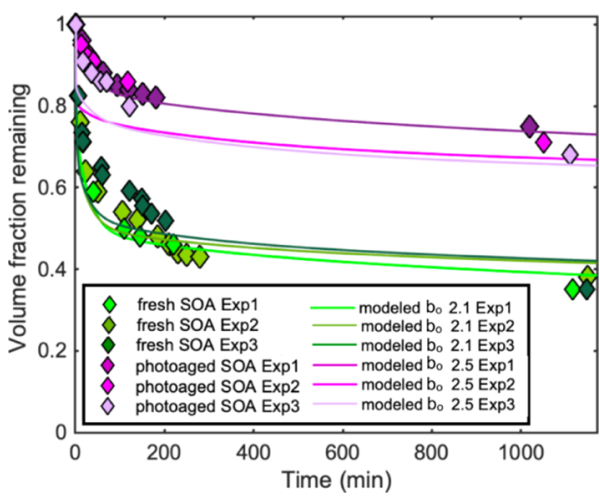

Figure 3. Evaporation kinetics of $\alpha$-pinene SOA before (green diamonds) and after photolysis (purple diamonds) plotted as remaining volume fraction as a function of time. Evaporation modeled based on Vaden et al. ${ }^{29}$ is shown as solid lines. The parameter $b_{\mathrm{O}}$ in the $\log \left(C^{*}\right)$ estimates (eq 2) was varied to match the evaporation kinetics observed.

(VFR) defined as $\left(d_{(t)} / d_{(t=0)}\right)^{3}$ is shown as a function of evaporation time. For particles that were not irradiated, we observe an initial rapid evaporation phase, during which 50$60 \%$ of the particle mass evaporates within $2 \mathrm{~h}$ (green diamonds). A period of slower evaporation follows, consistent with the evaporation kinetics of $\alpha$-pinene SOA presented in previous studies. $^{32,33}$ The fraction remaining for high loading experiments is slightly lower compared to the low loading experiment, consistent with the presence of additional semivolatile species at higher loadings. The evaporation behavior of photoaged particles (purple diamonds) is different. There is no fast evaporation phase, and after $3 \mathrm{~h}$, only $\sim 15-20 \%$ of the volume is lost. This corresponds to a threefold decrease in the fraction evaporating compared to the nonphotolyzed SOA, similar to recent measurements performed on photoaged $\alpha$ pinene SOA. ${ }^{11,12}$ Nearly identical evaporation behavior is seen for all three experiments, suggesting no dependency on mass loading. It should be noted that the evaporation kinetics of darkaged SOA were nearly identical to their unaged counterparts (Figure S8). We do observe a slightly reduced volatility after 1.5 $\mathrm{h}$ of dark aging, but the change is negligible compared to the changes for photoaged particles (Figure S8).

A simple kinetic model was applied to explain the observed evaporation kinetics of $\alpha$-pinene SOA, and it is shown in Figure 3 as solid green and purple lines for non-photoaged and photoaged SOA, respectively. The model is based on Vaden et al. $^{33}$ and Saha and Grieshop, ${ }^{34}$ using a mass accommodation coefficient $(\alpha)$ of 1.0 and saturation vapor concentrations $\left(C^{*}\right)$ calculated from the parameterization of Donahue et al., ${ }^{35}$ which are in turn based on the organic aerosol chemical composition (i.e., molecular formula) resolved by the EESI-TOF. Equal sensitivity in the EESI-TOF for all ions was assumed. This evaporation model is used for its simplicity; it assumes equilibrium partitioning, without kinetic limitations in the bulk phase, and does not fully capture nearly size-independent evaporation kinetics of $\alpha$-pinene SOA. ${ }^{36}$ The relationship between $C^{*}$ and the compounds' elemental composition is shown in eq 2, where $n_{\mathrm{C}}$ and $n_{\mathrm{O}}$ correspond to the number of carbon and oxygen atoms, respectively, with $b_{\mathrm{C}}=0.475, b_{\mathrm{CO}}=$ -0.3 , and $b_{\mathrm{O}}=2.1-2.5$. The parameter $b_{\mathrm{O}}$ defines the decrease in the saturation concentration with the addition of oxygen. The value of 2.3 used in the original parameterization reflects the assumption that oxygenated functional groups have the same effect on volatility as do carboxylic acids. If oxygen addition instead reflects the addition of different functionalities, a different value of $b_{\mathrm{O}}$ is required. Here, we have empirically adjusted $b_{\mathrm{O}}$ on an experiment-by-experiment basis in order to fit the measured effective volatility. The evaporation data are consistent with $b_{\mathrm{O}}=2.1$ and 2.5 for the periods before and after photolysis, respectively. To explain the evaporation rates observed before and after photolysis, the dependence of log $C^{*}$ with addition of one oxygen needs to increase from 2.1 (before photolysis) to 2.5 (after photolysis, see Figure S9). This suggests that photolysis may increase the fraction of carboxylic acid groups in the organic molecules, consistent with the AMS measurements presented here (Figure S2) and in Walhout et al. $^{21}$ Also, increase of volatile organics likely released from the particle upon irradiation is observed by the PTR similar to Malecha and Nizkorodov ${ }^{7}$ (Figure S10).

$$
\log C^{*}=\left(25-n_{\mathrm{C}}\right) * b_{\mathrm{C}}-n_{\mathrm{O}} b_{\mathrm{O}}-2 \frac{n_{\mathrm{C}} n_{\mathrm{O}}}{n_{\mathrm{C}}+n_{\mathrm{O}}} * b_{\mathrm{CO}}
$$

Another hypothesis to explain the decrease in the volatility of photoaged-SOA is kinetic limitations due to a change in the physical properties of the particle itself, such as an increase in viscosity. Yli-Juuti et al. ${ }^{37}$ modeled the evaporation of particles by lowering the viscosity by 3 orders of magnitude $\left(10^{4}\right.$ and $10^{7}$ $\mathrm{Pa} \mathrm{sec}$ ); however, this change could not explain the evaporation behavior observed in their study. Based on the parameterization performed by DeRieux et al., ${ }^{38}$ the change in the SOA molecular composition detected by the EESI would yield a change in viscosity from $10^{5}$ to $10^{7} \mathrm{~Pa}$ sec. Although the actual viscosity may differ from the parameterized viscosity, a change in viscosity alone is not sufficient to fully explain the results presented here, even if the parameterization were to underestimate the real viscosity by orders of magnitude.

Despite the less significant apparent decay in SOA mass and molecular ions at low loading, similar changes in volatility still occur (Figure 3), consistent with compositional changes observed by the AMS (Figure S2). Such strong reduction in volatility with photolysis at low SOA loading indicates a stronger change in the compounds' chemical composition than expected based on the observed decay from EESI measurements (Figure 2 ) and may reflect changes in functional group distribution of the detected species without a change in their elemental composition. The results from evaporation experiments generally imply that due to photolysis, SOA will be longer lived than anticipated in the atmosphere most likely due to a change in the molecules' functional group composition.

\section{IMPLICATIONS}

We compared the $J_{S O A}$ chamber values obtained under our conditions at high mass concentration with theoretical values 
(denoted $J_{\text {SOA,theor }}$ ), which are calculated based on the effective mass absorption cross section (MAC) of the bulk $\alpha$-pinene SOA measured by Romonosky et al. ${ }^{39}$ These values should be considered as upper limits as we assume effective quantum yields of unity, similar to small aldehydes. ${ }^{40}$ For this calculation, we assumed an average molecular weight of $270 \mathrm{~g} \mathrm{~mol}^{-1}$ and accounted for enhanced absorption in the particle phase due to scattering using Mie calculations. ${ }^{47}$ We note that the latter effect is trivial for the particle diameter of $120 \mathrm{~nm}$ under our conditions and implies an enhancement factor of the MAC values measured in diluted solutions of less than 1.2. The $J_{\mathrm{SOA} \text {,theor }}$ value obtained is $3.3 \times 10^{-4} \mathrm{~s}^{-1}$, a factor of $\sim 2$ lower than the measured values. We note that the measured photolysis rates refer only to the reactive fraction, while $\sim 60 \%$ of the total mass and EESI-TOF ion signals remain at the end of the experiments. If a substantial fraction of the SOA is not light-absorbing in the relevant wavelength range, MAC values would be lower than expected based on the measured $J_{\text {SOA,chamber }}$

The calculated gas-phase photolysis rates for hydrogen peroxide $\left(J_{\mathrm{H}_{2} \mathrm{O}_{2}}=2 \times 10^{-6} \mathrm{~s}^{-1}\right)$, formaldehyde $\left(J_{\mathrm{HCOH}}=2 \times\right.$ $\left.10^{-5} \mathrm{~s}^{-1}\right)$, acetone $\left(J_{\mathrm{C}_{3} \mathrm{H}_{6} \mathrm{O}}=1.8 \times 10^{-6}\right)$, and pinonaldehyde $\left(J_{\mathrm{C}_{10} \mathrm{H}_{16} \mathrm{O}_{2}}=1.4 \times 10^{-5} \mathrm{~s}^{-1}\right)$, taking the absorption cross sections and quantum yield dependence on the wavelength provided in the literature, ${ }^{41,42}$, are $\sim 30$ to 300 times lower than the $J$ measured for the particle-phase species. Most of the literature assumes that the photolysis of SOA must be in the same range because it contains similar functional groups; the results presented here show that this is not the case and reveal the species on a molecular level, which are most affected by photolysis. Interactions between chromophores and other functional groups present in the same molecule can result in enhancements in the absorption cross sections. For example, the carbonyl group of $\alpha$-hydroperoxycarbonyls can provide $2-4$ times stronger absorption than a ketone/aldehyde alone. ${ }^{37}$ For comparison, the calculated $J$ using the absorption cross section for a mixture of ketohydroperoxides in a solution of acetonitrile reported by Jorand et al. is $3.5 \times 10^{-5} \mathrm{~s}^{-1}$. ${ }^{43}$ This value is slower than the atmospheric photolysis rates of $\alpha$-hydroperoxycarbonyls $\left(1-5 \times 10^{-4} \mathrm{~s}^{-1}\right),{ }^{44}$ which are similar to the range of values reported here with comparable wavelength ranges.

The photolysis rates reported here compete with other organic aerosol aging mechanisms such as heterogeneous oxidation by $\mathrm{OH}$. The photolytic lifetimes determined in this study lie between $\sim 15$ and $90 \mathrm{~min}$ at a $J_{\mathrm{NO}_{2}}$ of $3 \times 10^{-3} \mathrm{~s}^{-1}$. Although the photosensitive mass fraction is inversely related to SOA concentration, even the low-loading (ambient-relevant) experiments show detectable compositional changes and a decrease in volatility comparable to that of the high-loading experiments. In contrast, $\mathrm{OH}$ oxidation lifetimes are on the order of $\sim 6$ days ${ }^{35}$ and potentially surface-limited, although capable of affecting a larger molecular ensemble. Therefore, photolysis is likely a significant aging process of SOA in the particle phase. As the residence time of submicrometer particles in the atmosphere is on average 1 week, photolysis will play an important role in the evolution of organic aerosols in the atmosphere and should be considered when representing SOA in models.

Since photolysis efficiently removes the optically active particle-phase species, the optical properties of the aerosol will also be altered, reducing the absorbance of solar light in the nearUV range. Particle-phase photochemistry will affect the distribution of both condensed- and gas-phase species, leading to a change in the SOA chemical composition, volatility, oxidation state, mass loss, and atmospheric lifetime. Here, we demonstrate that photolysis lowers the volatility of particles, regardless of whether mass is lost during the process, creating particle mass that will be more long-lived in the atmosphere. However, this study addresses only $\alpha$-pinene SOA, and a deeper quantitative understanding is likewise needed for other types of SOA across a range of atmospherically relevant mass loadings, including precursors of anthropogenic origin for which the absorption cross sections are orders of magnitude higher. ${ }^{39}$ Finally, understanding the structure and functionality of the groups that are most active during photolysis is the next step to fully elucidate the underlying chemistry taking place.

\section{ASSOCIATED CONTENT}

\section{SI Supporting Information}

The Supporting Information is available free of charge at https://pubs.acs.org/doi/10.1021/acs.est.0c06752.

Additional experimental description; decay rates of the mass concentrations, as measured by the SMPS and the AMS, and the total EESI-TOF signal for the three experiments; overview of experimental conditions before $\left(t_{0}\right)$ and after $(t) 1.5 \mathrm{~h}$ of irradiation; comparison of decay rates for dark aging and aging under UV irradiation; time evolution of mean diameter for experiments at three different total mass loadings; aerosol composition measured by the AMS for three experiments with different mass loadings; time evolution of selected ions measured by the EESI-TOF before and after the irradiation; time evolution of selected species during experiment 2 ; fraction of the signal remaining for selected ions for UV and dark heated experiment; carbon and oxygen distribution measured by the EESI prior to photolysis and after photolysis; mixing ratios of $\alpha$-pinene, ozone, $\mathrm{RH}$, and temperature in the chamber; VFR of $\alpha$-pinene SOA in the evaporation chamber for the experiment with lights on and a repeat experiment where SOA was aged under dark conditions; the dependence of the logarithm of saturation vapor concentration of $\mathrm{C}_{10}$ compounds on the number of added oxygens to the molecule; time evolution of selected gas-phase species monitored by the PTR for experiment 1 ; volatility distribution using the parameterization of Donahue et al. (PDF)

\section{AUTHOR INFORMATION}

\section{Corresponding Authors}

David M. Bell - Laboratory of Atmospheric Chemistry, Paul Scherrer Institute, 5232 Villigen, Switzerland;

Email: david.bell@psi.ch

Jay G. Slowik - Laboratory of Atmospheric Chemistry, Paul Scherrer Institute, 5232 Villigen, Switzerland;

Email: jay.slowik@psi.ch

\section{Authors}

Veronika Pospisilova - Laboratory of Atmospheric Chemistry, Paul Scherrer Institute, 5232 Villigen, Switzerland; Tofwerk, 3600 Thun, Switzerland; (1) orcid.org/0000-0003-25592252

Houssni Lamkaddam - Laboratory of Atmospheric Chemistry, Paul Scherrer Institute, 5232 Villigen, Switzerland

Amelie Bertrand - Laboratory of Atmospheric Chemistry, Paul Scherrer Institute, 5232 Villigen, Switzerland 
Liwei Wang - Laboratory of Atmospheric Chemistry, Paul Scherrer Institute, 5232 Villigen, Switzerland; (1) orcid.org/ 0000-0001-8997-3316

Deepika Bhattu - Laboratory of Atmospheric Chemistry, Paul Scherrer Institute, 5232 Villigen, Switzerland; Department of Civil and Infrastructure Engineering, Indian Institute of Technology Jodhpur, Karwar 342037, India; 10 orcid.org/ 0000-0003-3597-190X

Xueqin Zhou - Laboratory of Atmospheric Chemistry, Paul Scherrer Institute, 5232 Villigen, Switzerland

Josef Dommen - Laboratory of Atmospheric Chemistry, Paul Scherrer Institute, 5232 Villigen, Switzerland; (1) orcid.org/ 0000-0002-0006-0009

Andre S.H. Prevot - Laboratory of Atmospheric Chemistry, Paul Scherrer Institute, 5232 Villigen, Switzerland; (1) orcid.org/0000-0002-9243-8194

Urs Baltensperger - Laboratory of Atmospheric Chemistry, Paul Scherrer Institute, 5232 Villigen, Switzerland

Imad El Haddad - Laboratory of Atmospheric Chemistry, Paul Scherrer Institute, 5232 Villigen, Switzerland; (1) orcid.org/ 0000-0002-2461-7238

Complete contact information is available at: https://pubs.acs.org/10.1021/acs.est.0c06752

\section{Notes}

The authors declare no competing financial interest.

\section{ACKNOWLEDGMENTS}

We thank Markus Müller (Ionicon, Innsbruck) for the help during performed chamber experiments. This work was supported by the Swiss National Science Foundation (starting grant BSSGI0_155846, grant 200020_172602, SSSTC grant IZLCZ2_169986, and grant 200020_188624) and the European Union's Horizon 2020 Research and Innovation Program through the EUROCHAMP-2020 Infrastructure Activity under grant agreement no. 730997.

\section{REFERENCES}

(1) IPCC, Summary for Policymakers. Climate Change 2013: The Physical Science Basis; Stocker, T., et al., Eds; Cambridge Univ Press: New York, 2013; pp 1-29.

(2) Hallquist, M.; Wenger, J. C.; Baltensperger, U.; Rudich, Y.; Simpson, D.; Claeys, M.; Dommen, J.; Donahue, N. M.; George, C.; Goldstein, A. H.; Hamilton, J. F.; Herrmann, H.; Hoffmann, T.; Iinuma, Y.; Jang, M.; Jenkin, M. E.; Jimenez, J. L.; Kiendler-Scharr, A.; Maenhaut, W.; McFiggans, G.; Mentel, T. F.; Monod, A.; Prévôt, A. S. H.; Seinfeld, J. H.; Surratt, J. D.; Szmigielski, R.; Wildt, J. The formation, properties and impact of secondary organic aerosol: current and emerging issues. Atmos. Chem. Phys. 2009, 9, 5155-5236.

(3) Jimenez, J. L.; Canagaratna, M. R.; Donahue, N. M.; Prevot, A. S. H.; Zhang, Q.; Kroll, J. H.; DeCarlo, P. F.; Allan, J. D.; Coe, H.; Ng, N. L.; Aiken, A. C.; Docherty, K. S.; Ulbrich, I. M.; Grieshop, A. P.; Robinson, A. L.; Duplissy, J.; Smith, J. D.; Wilson, K. R.; Lanz, V. A.; Hueglin, C.; Sun, Y. L.; Tian, J.; Laaksonen, A.; Raatikainen, T.; Rautiainen, J.; Vaattovaara, P.; Ehn, M.; Kulmala, M.; Tomlinson, J. M.; Collins, D. R.; Cubison, M. J.; Dunlea, J.; Huffman, J. A.; Onasch, T. B.; Alfarra, M. R.; Williams, P. I.; Bower, K.; Kondo, Y.; Schneider, J.; Drewnick, F.; Borrmann, S.; Weimer, S.; Demerjian, K.; Salcedo, D.; Cottrell, L.; Griffin, R.; Takami, A.; Miyoshi, T.; Hatakeyama, S.; Shimono, A.; Sun, J. Y.; Zhang, Y. M.; Dzepina, K.; Kimmel, J. R.; Sueper, D.; Jayne, J. T.; Herndon, S. C.; Trimborn, A. M.; Williams, L. R.; Wood, E. C.; Middlebrook, A. M.; Kolb, C. E.; Baltensperger, U.; Worsnop, D. R. Evolution of organic aerosols in the atmosphere. Science 2009, 326, 1525-1529.
(4) Mutzel, A.; Poulain, L.; Berndt, T.; Iinuma, Y.; Rodigast, M.; Böge, O.; Richters, S.; Spindler, G.; Sipilä, M.; Jokinen, T.; Kulmala, M.; Herrmann, H. Highly Oxidized Multifunctional Organic Compounds Observed in Tropospheric Particles: A Field and Laboratory Study. Environ. Sci. Technol. 2015, 49, 7754-7761.

(5) Krapf, M.; El Haddad, I.; Bruns, E. A.; Molteni, U.; Daellenbach, K. R.; Prévôt, A. S. H.; Baltensperger, U.; Dommen, J. Labile Peroxides in Secondary Organic Aerosol. Chem 2016, 1, 603-616.

(6) Pospisilova, V.; Lopez-Hilfiker, F. D.; Bell, D. M.; El Haddad, I.; Mohr, C.; Huang, W.; Heikkinen, L.; Xiao, M.; Dommen, J.; Prevot, A. S. H.; Baltensperger, U.; Slowik, J. G. On the fate of oxygenated organic molecules in atmospheric aerosol particles. Sci. Adv. 2020, 6, No. eaax8922.

(7) Malecha, K. T.; Nizkorodov, S. A. Photodegradation of secondary organic aerosol particles as a source of small, oxygenated volatile organic compounds. Environ. Sci. Technol. 2016, 50, 9990-9997.

(8) Walser, M. L.; Park, J.; Gomez, A. L.; Russell, A. R.; Nizkorodov, S. A. Photochemical Aging of Secondary Organic Aerosol Particles Generated from the Oxidation of d-Limonene. J. Phys. Chem. A 2007, 111, 1907-1913.

(9) Mang, S. A.; Henricksen, D. K.; Bateman, A. P.; Andersen, M. P. S.; Blake, D. R.; Nizkorodov, S. A. Contribution of Carbonyl Photochemistry to Aging of Atmospheric Secondary Organic Aerosol. J. Phys. Chem. A 2008, 112, 8337-8344.

(10) Pan, X.; Underwood, J. S.; Xing, J.-H.; Mang, S. A.; Nizkorodov, S. A. Photodegradation of secondary organic aerosol generated from limonene oxidation by ozone studied with chemical ionization mass spectrometry. Atmos. Chem. Phys. 2009, 9, 3851-3865.

(11) Zawadowicz, M. A.; Lee, B. H.; Shrivastava, M.; Zelenyuk, A.; Zaveri, R. A.; Flynn, C.; Thornton, J. A.; Shilling, J. E. Photolysis Controls Atmospheric Budgets of Biogenic Secondary Organic Aerosol. Environ. Sci. Technol. 2020, 54, 3861-3870.

(12) Shilling, J. E.; Zawadowicz, M. A.; Liu, J.; Zaveri, R. A.; Zelenyuk, A. Photochemical Aging Alters Secondary Organic Aerosol Partitioning Behavior. ACS Earth Space Chem. 2019, 3, 2704-2716.

(13) Atkinson, R.; Baulch, D.; Cox, R.; Hampson, F. J.; Kerr, J.; Rossi, M.; Troe, J. Evaluated Kinetic and Photochemical Data for Atmospheric Chemistry: Supplement VI. IUPAC Subcommittee on Gas Kinetic Data Evaluation for Atmospheric Chemistry. J. Phys. Chem. Ref. Data 1997, 29, 167-266.

(14) Finlayson-Pitts, B. J.; Pitts, N. J., Jr. Chemistry of Upper and Lower Atmosphere; Academic Press, 2000.

(15) Edwards, P. M.; Brown, S. S.; Roberts, J. M.; Ahmadov, R.; Banta, R. M.; deGouw, J. A.; Dubé, W. P.; Field, R. A.; Flynn, J. H.; Gilman, J. B.; Graus, M.; Helmig, D.; Koss, A.; Langford, A. O.; Lefer, B. L.; Lerner, B. M.; Li, R.; Li, S.-M.; McKeen, S. A.; Murphy, S. M.; Parrish, D. D.; Senff, C. J.; Soltis, J.; Stutz, J.; Sweeney, C.; Thompson, C. R.; Trainer, M. K.; Tsai, C.; Veres, P. R.; Washenfelder, R. A.; Warneke, C.; Wild, R. J.; Young, C. J.; Yuan, B.; Zamora, R. High winter ozone pollution from carbonyl photolysis in an oil and gas basin. Nature 2014, $514,351$.

(16) Presto, A. A.; Huff Hartz, K. E.; Donahue, N. M. Secondary Organic Aerosol Production from Terpene Ozonolysis. 1. Effect of UV Radiation. Environ. Sci. Technol. 2005, 39, 7036-7045.

(17) Wong, J. P. S.; Zhou, S.; Abbatt, J. P. D. Changes in secondary organic aerosol composition and mass due to photolysis: relative humidity dependence. J. Phys. Chem. A 2015, 119, 4309-4316.

(18) Epstein, S. A.; Blair, S. L.; Nizkorodov, S. A. Direct Photolysis of $\alpha$-Pinene Ozonolysis Secondary Organic Aerosol: Effect on Particle Mass and Peroxide Content. Environ. Sci. Technol. 2014, 48, 1125111258

(19) Bateman, A. P.; Nizkorodov, S. A.; Laskin, J.; Laskin, A. Photolytic processing of secondary organic aerosols dissolved in cloud droplets. Phys. Chem. Chem. Phys. 2011, 13, 12199-12212.

(20) O'Brien, E. R.; Kroll, J. H. Photolytic Aging of Secondary Organic Aerosol: Evidence for a Substantial Photo-Recalcitrant Fraction. J. Phys. Chem. Lett. 2019, 10, 4003-4009.

(21) Walhout, E. Q.; Yu, H.; Thrasher, C.; Shusterman, J. M.; O’Brien, R. E. Effects of Photolysis on the Chemical and Optical Properties of 
Secondary Organic Material Over Extended Time Scales. ACS Earth Space Chem. 2019, 3, 1226-1236.

(22) Guzmán, M. I.; Colussi, A. J.; Hoffmann, M. R. Photoinduced oligomerization of aqueous pyruvic acid. J. Phys. Chem. A 2006, 110, 3619-3626.

(23) Perri, M. J.; Seitzinger, S.; Turpin, B. J. Secondary organic aerosol production from aqueous photooxidation of glycolaldehyde: Laboratory experiments. Atmos. Environ. 2009, 43, 1487-1497.

(24) Hinks, M. L.; Brady, M. V.; Lignell, H.; Song, M.; Grayson, J. W.; Bertram, A. K.; Lin, P.; Laskin, A.; Laskin, J.; Nizkorodov, S. A. Effect of viscosity on photodegradation rates in complex secondary organic aerosol materials. Phys. Chem. Chem. Phys. 2016, 18, 8785-8793.

(25) Lignell, H.; Hinks, M. L.; Nizkorodov, S. A. Exploring matrix effects on photochemistry of organic aerosols. Proc. Natl. Acad. Sci. U.S.A. 2014, 111, 13780.

(26) Lopez-Hilfiker, F. D.; Pospisilova, V.; Huang, W.; Kalberer, M.; Mohr, C.; Stefenelli, G.; Thornton, J. A.; Baltensperger, U.; Prevot, A. S. H.; Slowik, J. G. An Extractive Electrospray Ionization Time-of-Flight Mass Spectrometer (EESI-TOF) for online measurement of atmospheric aerosol particles. Atmos. Meas. Tech. 2019, 12, 4867-4886.

(27) Jordan, A.; Haidacher, S.; Hanel, G.; Hartungen, E.; Märk, L.; Seehauser, H.; Schottkowsky, R.; Sulzer, P.; Märk, T. D. A high resolution and high sensitivity proton-transfer-reaction time-of-flight mass spectrometer (PTR-TOF-MS). Int. J. Mass Spectrom. 2009, 286, $122-128$.

(28) Platt, S. M.; El Haddad, I.; Zardini, A. A.; Clairotte, M.; Astorga, C.; Wolf, R.; Slowik, J. G.; Temime-Roussel, B.; Marchand, N.; Ježek, I.; Drinovec, L.; Močnik, G.; Möhler, O.; Richter, R.; Barmet, P.; Bianchi, F.; Baltensperger, U.; Prévôt, A. S. H. Secondary organic aerosol formation from gasoline vehicle emissions in a new mobile environmental reaction chamber. Atmos. Chem. Phys. 2013, 13, 9141-9158.

(29) DeCarlo, P. F.; Kimmel, J. R.; Trimborn, A.; Northway, M. J.; Jayne, J. T.; Aiken, A. C.; Gonin, M.; Fuhrer, K.; Horvath, T.; Docherty, K. S.; Worsnop, D. R.; Jimenez, J. L. Field-Deployable, HighResolution, Time-of-Flight Aerosol Mass Spectrometer. Anal. Chem. 2006, 78, 8281-8289.

(30) Junninen, H.; Ehn, M.; Petäjä, T.; Luosujärvi, L.; Kotiaho, T.; Kostiainen, R.; Rohner, U.; Gonin, M.; Fuhrer, K.; Kulmala, M.; Worsnop, D. R. A high-resolution mass spectrometer to measure atmospheric ion composition. Atmos. Meas. Tech. 2010, 3, 1039-1053.

(31) Henry, K. M.; Donahue, N. M. Photochemical Aging of $\alpha$-Pinene Secondary Organic Aerosol: Effects of $\mathrm{OH}$ Radical Sources and Photolysis. J. Phys. Chem. A 2012, 116, 5932-5940.

(32) Wilson, J.; Imre, D.; Beránek, J.; Shrivastava, M.; Zelenyuk, A. Evaporation kinetics of laboratory-generated secondary organic aerosols at elevated relative humidity. Environ. Sci. Technol. 2015, 49, 243-249.

(33) Vaden, T. D.; Imre, D.; Beranek, J.; Shrivastava, M.; Zelenyuk, A. Evaporation kinetics and phase of laboratory and ambient secondary organic aerosol. Proc. Natl. Acad. Sci. U. S. A. 2011, 108, 2190-2195.

(34) Saha, P. K.; Grieshop, A. P. Exploring Divergent Volatility Properties from Yield and Thermodenuder Measurements of Secondary Organic Aerosol from $\alpha$-Pinene Ozonolysis. Environ. Sci. Technol. 2016, 50, 5740-5749.

(35) Donahue, N. M.; Chuang, W.; Epstein, S. A.; Kroll, J. H.; Worsnop, D. R.; Robinson, A. L.; Adams, P. J.; Pandis, S. N. Why do organic aerosols exist? Understanding aerosol lifetimes using the twodimensional volatility basis set. Environ. Chem. 2013, 10, 151-157.

(36) Bell, D. M.; Imre, D.; Martin, S. T.; Zelenyuk, A. The properties and behavior of $\alpha$-pinene secondary organic aerosol particles exposed to ammonia under dry conditions. Phys. Chem. Chem. Phys. 2017, 19, 6497-6507.

(37) Yli-Juuti, T.; Pajunoja, A.; Tikkanen, O.-P.; Buchholz, A.; Faiola, C.; Väisänen, O.; Hao, L.; Kari, E.; Peräkylä, O.; Garmash, O.; Shiraiwa, M.; Ehn, M.; Lehtinen, K.; Virtanen, A. Factors controlling the evaporation of secondary organic aerosol from $\alpha$-pinene ozonolysis. Geophys. Res. Lett. 2017, 44, 2562-2570.

(38) DeRieux, W.-S. W.; Li, Y.; Lin, P.; Laskin, J.; Laskin, A.; Bertram, A. K.; Nizkorodov, S. A.; Shiraiwa, M. Predicting the glass transition temperature and viscosity of secondary organic material using molecular composition. Atmos. Chem. Phys. 2018, 18, 6331-6351.

(39) Romonosky, D. E.; Ali, N. N.; Saiduddin, M. N.; Wu, M.; Lee, H. J.; Aiona, P. K.; Nizkorodov, S. A. Effective absorption cross sections and photolysis rates of anthropogenic and biogenic secondary organic aerosols. Atmos. Environ. 2016, 130, 172-179.

(40) Röth, E.-P.; Ehhalt, D. H. A simple formulation of the CH2O photolysis quantum yields. Atmos. Chem. Phys. 2015, 15, 7195-7202.

(41) Meller, R.; Moortgat, G. K. Temperature dependence of the absorption cross sections of formaldehyde between 223 and $323 \mathrm{~K}$ in the wavelength range 225-375 nm. J. Geophys. Res. Atmos. 2000, 105, $7089-7101$.

(42) Vaghjiani, G. L.; Turnipseed, A. A.; Warren, R. F.; Ravishankara, A. R. Photodissociation of $\mathrm{H} 2 \mathrm{O} 2$ at 193 and $222 \mathrm{~nm}$ : Products and quantum yields. J. Chem. Phys. 1992, 96, 5878-5886.

(43) Jorand, F.; Kerhoas, L.; Heiss, A.; Einhorn, J.; Sahetchian, K. Determination of the ultra violet absorption cross section of hexylketohydroperoxides in solution in acetonitrile. J. Photochem. Photobiol. Chem. 2000, 134, 119-125.

(44) Liu, Z.; Nguyen, V. S.; Harvey, J.; Müller, J.-F.; Peeters, J. The photolysis of $\alpha$-hydroperoxycarbonyls. Phys. Chem. Chem. Phys. 2018, 20, 6970-6979.

(45) Walhout, E. Q.; Dorn, S. E.; Martens, J.; Berden, G.; Oomens, J.; Cheong, P. H.-Y.; Kroll, J. H.; O’Brien, R. E. Infrared Ion Spectroscopy of Environmental Organic Mixtures: Probing the Composition of $\alpha$ Pinene Secondary Organic Aerosol. Environ. Sci. Technol. 2019, 53, $7604-7612$.

(46) Kourtchev, I.; Doussin, J.-F.; Giorio, C.; Mahon, B.; Wilson, E. M.; Maurin, N.; Pangui, E.; Venables, D. S.; Wenger, J. C.; Kalberer, M. Molecular composition of fresh and aged secondary organic aerosol from a mixture of biogenic volatile compounds: a high-resolution mass spectrometry study. Atmos. Chem. Phys. 2015, 15, 5683-5695.

(47) Moschos, V.; Gysel-Beer, M.; Modini, R. L.; Corbin, J. C.; Massabò, D.; Costa, C.; Danelli, S. G.; Vlachou, A.; Daellenbach, K. R.; Szidat, S.; Prati, P.; Prévôt, A. S. H.; Baltensperger, U.; El Haddad, I.: Source-specific light absorption by carbonaceous components in the complex aerosol matrix from yearly filter-based measurements, Atmospheric Chemistry and Physics Discussion; EGU publications, 2020.

\section{NOTE ADDED AFTER ISSUE PUBLICATION}

This article was initially published with an incorrect copyright statement and was corrected on or around May 28, 2021. 